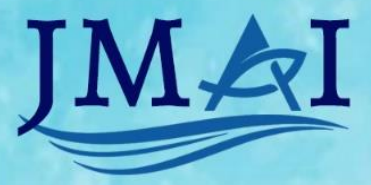

Jurnal Media Akwakultur

DN D O ON ESA A

https://journal.unram.ac.id/index.php/jmai/index. E-ISSN : 2798-0553

VOLUME 1, NOMOR 1, JUNI 2021

\title{
POTENSI BUDIDAYA IKAN BANDENG SEBAGAI PEMANFAATAN PLANKTON DI PERAIRAN BATU NAMPAR
}

\author{
Nanda Diniarti ${ }^{*}$, Muhammad Junaidi $^{1}$, Baiq Hilda Astriana ${ }^{2}$ \\ 1Program Studi Budidaya Perairan Universitas Mataram \\ 2Proram Studi Ilmu Kelautan Universitas Mataram \\ Jalan Pendidikan No.37 Mataram \\ *Alamat korespondensi : nandadiniarti@unram.ac.id
}

\begin{abstract}
ABSTRAK
Perairan Teluk Ekas memiliki konsentrasi nutrien yang tinggi yang berasal dari kegiatan pembudidaya ikan pada Karamba jaring Apung. Nutrien yang berlebihan di perairan akan memicu terjadinya blooming plankton. Plankton yang tumbuh dapat dikendalikan dengan memberikan organisme yang dapat memanfaatkan keberadaannya sebagai pakan, salah satunya adalah ikan bandeng. Tujuan penelitian ini adalah mengiventaris/mendata jenis plankton di perairan Batu Nampar serta melihat kesesuaian jenis plankton yang ada dengan yang menjadi dapat menjadi pakan ikan alami Bandeng. Metode yang digunakan dalam penelitian ini adalah metode survey. Pengamatan lebih dititikberatkan pada pendataan jenis plankton. Pengambilan contoh air dan pengamatan terhadap parameter-parameter kualitas air lainnya dilakukan pada tiap bulan selama 3 kali. Jenis plankton yang teriventarisir pada saat penelitian adalah: Synedra ulna, Fragilaria, Hemiaulus sinensis, Skeletonema costatum, Triceratium taves, Coscinodiscus granii, Pseudo nitzschia, Dytilum sol, Cerataulina smithii, Clamydocapsa sp, Navicula elegans, Aulacodiscus gracilis, Cydotella sp., Globorotolia pumilio, Ceratium sp.,larva crustacean, Pontellina plumata. Plankton yang terdapat lebih banyak dari Bacillariophyceae yang merupakan jenis pakan dari ikan bandeng sehingga perairan KJA Batu Nampar berpotensi digunakan untuk budidaya Bandeng.
\end{abstract}

Kata Kunci Plankton, Kualitas air, nutrien, bandeng

Tracebility Tanggal diterima : 26 Mei 2021. Tanggal publikasi : 23 Juni 2021

Panduan Diniarti, N., Junaidi, M., \& Astriana, B.H. (2021). Potensi Budidaya Ikan Bandeng

Kutipan

(APPA $7^{\text {th }}$ )
Sebagai Pemanfaatan Plankton Di Perairan Batu Nampar. Jurnal Media Akuakultur Indonesia, $\quad 1 \quad$ (1), http://doi.org/10.29303/mediaakuakultur.v1i1.133 


\section{PENDAHULUAN}

Lebih dari dua dekade Teluk Ekas sebagai tempat berlangsungnya budidaya dengan sistem Karamba Jaring Apung. Jenis biota yang dibudidayakan berupa kerapu dan lobster. Biota yang dibudidayakan dengan sistem KJA diberi pakan berupa ikan rucah. Pakan yang diberikan tidak akan termakan oleh ikan, pasti ada yang terbuang sehingga menambah masukan bahan organik di perairan. Jumlah bahan organik yang lebih besar dari pada daya dukungnya akan membuat perubahan dalam kualitas air di perairan tersebut. Menurut Junaidi et al., 2014 bahwa perairan Batu Nampar tergolong perairan yang telah "tercemar sedang" berdasarkan indeks Storet. Secara alami bahan organik berasal dari eksresi biota budidaya serta matinya plankton. Masukan bahan organik yang masuk ke dalam perairan akan dirombak oleh detritus berupa komplek mikroorganisme menjadi bahan penyusunnya. Proses perombakan bahan organik ukuran besar menjadi bahan organik yang tersuspensi dapat menambah nilai kekeruhan di perairan. Selain itu hasil perombakan menjadi nutrien dapat menyokong tumbuhnya plankton secara berlebihan atau diistilahkan blooming algae.

Nutrien pada perairan Batu Nampar telah melebihi baku mutu yang di syaratkan pada Keputusan Menteri Lingkungan Hidup No.51 Tahun 2004 bila merujuk pada Setyowati, et al., (2013) dan Junaidi et al., (2014). Berlebihanya nutriet akan membuat plankton yang tumbuh subur. Pertumbuhan fitoplankton yang subur tetap akan dibatasi oleh parameter kualitas air lainnya. Tingginya jumlah plankton di perairan akan mengurangi penetrasi cahaya karena fitoplankton yang dipermukaan akan menutupi plankton yang ada di bawahnya serta dinamika jumlah oksigen terlarut akan sangat berfluktuasi. Pada malam hari sampai pagi hari sebelum ada sinar matahari maka oksigen akan berada di titik terendah dan pada siang hari pada saat sinar matahari maksimal maka kelarutan oksigen sampai saturasinya.

Nutrien yang terlanjur ada di perairan dapat dikurangi dengan cara memanen nutriet dalam biomasa dan mengurangi jumlah masukan bahan organik. Pemanenan nutrien dalam bentuk biomasa bisa dilakukan dengan melihat rantai pakan di perairan tersebut. Nutrien digunakan oleh fitoplankton kemudian berpindah pada konsumer tingkat pertama. Pemanenan fitoplankton mustahil dilakukan secara manual sehingga pemanenan dilakukan secaraq tidak langsung yaitu melalui konsumen tingkat pertama atau biota yang memakan fitoplankton atau herbivora.

Organisme herbivora biasanya memiliki cara makan filter feeder. Organisme ini dapat berupa ikan dan kekerangan. Namun biasanya untuk mengendalikan kepadatan plankton biasanya digunakan ikan planktivor. Ikan planktivor bisa dibudidayakan pada karamba jaring apung berdampingan dengan ikan utama budidaya. Budidaya ikan planktivor bertujuan untuk dapat memanfaatkan fitoplankton yang melimpah sehingga bisa mengurangi kelimpahan plankton.

Beberapa kali ikan digunakan sebagai pengendali pertumbuhan fitoplankton dan tumbuhan air di perairan tawar seperti restoking ikan mola di waduk cirata, penebaran 
bandeng pada waduk jatiluhur tahun 2001,2007 dan 2009 serta penebaran ikan nilem pada waduk cirata. Semua langkah tersebut diupayakan untuk mengedalikan status trofik perairan yang telah termasuk eutrofik agar tidak menjadi distrofik atau bisa menjadi mesotrofik.

Bandeng banyak digunakan sebagai pemanen /pemanfaatan fitoplankton baik diperairan tawar maupun laut. Bandeng merupakan ikan euryhalin atau memiliki rentang salinitas yang luas. Selain itu ikan bandeng merupakan ikan ekonomis penting.

Namun sebelum mengintroduksi ikan bandeng di KJA Batu Nampar perlu dilakukan analisa kesesuaian beberapa parameter lingkungan dan yang tidak kalah pentingnya adalah jenis fitoplankton yang bisa dimanfaatkan oleh bandeng. Oleh karena itu tujuan penelitian ini adalah mengiventaris/mendata jenis fitoplankton di perairan Batu Nampar.

\section{METODE}

Metode yang digunakan dalam penelitian ini adalah metode survey. Pengamatan lebih dititikberatkan pada pendataan jenis plankton. Pengambilan contoh air dan pengamatan terhadap parameter-parameter kualitas air lainnya dilakukan pada tiap bulan selama 3 kali.

\section{Identifikasi Plankton}

Pencacahan Plankton dilakukan dengan menggunakan metode sapuan dan kepadatan dinyatakan dalam satuan sel/ L. Jenis Plankton diidentifikasi menggunakan buku diidentifikasi Yamaji (1976) dan Omura et.a.,l (2012).Plankton akan dianalisa indeks lingkungannya dengan:

1. Kelimpahan Relatif (KR)

Penentuan kelimpahan relatif dihitung dengan menggunakan rumus menurut Dahuri (2003) sebagai berikut:

$$
\mathrm{KR}=\frac{\mathrm{a}}{\mathrm{a}+\mathrm{b}+\mathrm{c}} \times 100 \%
$$

Dimana :

a : Jumlah individu jenis tertentu yang ditemukan

a, b, c : Jumlah keseluruhan jenis-jenis yang ditemukan

2. Indeks keanekaragaman jenis atau indeks Shannon (H)

Indeks ini digunakan untuk mengetahui keanekaragaman hayati biota yang diteliti. Indeks keanekaragaman dihitung berdasarkan rumus Shannon \& Weiner ( Abel 1989).

$$
H=\sum_{l=1}^{s} P i \cdot L n P i \longrightarrow P i=\frac{n i}{N}
$$




\section{Dimana :}

$\mathrm{Pi}=$ kelimpahan relatif dari jenis biota ke-i yang besarnya $0,0-1,0$

ni $=$ jumlah sel suatu jenis

$\mathrm{N}$ = jumlah sel dari seluruh jenis yang ada dalam contoh

$\mathrm{S}=$ jumlah jenis biota dalam contoh

Kriteria hasil keanekaragaman (H') berdasarkan Shannon-Wiener (Krebs 1989) adalah:

$\mathrm{H}^{\prime} \leq 3.32$ : Keanekaragamn rendah

$3.32<\mathrm{H}^{\prime}<9.97$ : keanekaragaman sedang

$\mathrm{H}^{\prime} \geq 9.97 \quad$ : keanekaragaman tinggi

3. Indeks dominansi (D) dihitung menurut Odum (1971).

Indeks ini digunakan untuk mengetahui dominansi jenis biota yang diteliti.

Dominansi jenis dihitung berdasarkan rumus indeks dominansi Simpson, yaitu

$\mathrm{D}=\Sigma\left(\mathrm{Pi}^{2}\right) \quad \mathrm{Pi}=\mathrm{ni} / \mathrm{N}$

Dimana :

ni $=$ jumlah individu ke-i

$\mathrm{N}$ = jumlah individu dari seluruh jenis yang ada dalam contoh

Kriteria Indeks Dominansi Simpson dibagi menjadi 3 kategori (Odum, 1993) :

$\mathrm{D}^{\prime}=0-0,30=$ Dominansi Rendah

$\mathrm{D}^{\prime}=0,31-0,60=$ Dominansi Sedang

$\mathrm{D}^{\prime}=0,61-1,0=$ Dominansi Tinggi

\section{Jenis Plankton}

\section{HASIL DAN PEMBAHASAN}

Dari hasil pengamatan didapatkan 17 jenis plankton yang terdiri dari 6 kelas seperti pada Gambar 2. Kelas yang terbanyak terkoleksi adalah Bacillariophyceae dengan kelimpahan 325 sel / L. Bacillariophyceae adalah pakan alami biota yang hidup di laut dan populasinya tinggi di perairan payau dan laut dan dikenal dengan diatom. Sel diatom dilapisi dinding sel yang berasal dari silica. Diatom mampu mengadakan fotosintesis karena mengandung klorofil. Secara umumnya diatom dibagi menjadi tiga ordo yaitu Coscinodiscacea, diatom yang bundar dan memiliki bentuk tubuh simetri radial, Fragilariaceae, diatom pen tanpa rafe yang bebrbentuk simetri bilateral dan Bacillariceae, diatom pen dengan rafe. Genera dari kelas Bacillariophyceae di Perairan Batunampar terdiri dari 12 dan banyak berupa diatom pennales/jarum. Plankton dari kelas Chlorophyceae merupakan kelas dengan jumlah kedua terbanyak.

Adanya kehadiran kelas Dinophyceae merupakan pertanda buruk bagi sumberdaya perairan dan harus ditindak lanjuti agar tidak menjadi blooming. Hal ini dikuatkan oleh Cokrowati et al. (2015), bahwa perairan Batunampar Selatan berpotensi untuk munculnya Harmful Algae Bloom's (HABs). Ganggang tertentu merupakan pertanda bahwa 
keseimbangan lingkungan di perairan telah rusak sehingga kondisinya hanya menguntungkan beberapa jenis ganggang.

Selain plankton dari jenis fitoplankton terkoleksi juga plankton hewani/zooplankton. Ada dua kelas yang tergabung dalam kelompok zooplankton yaitu larva crustacea dan Hexanauplia. Larva crustacean diduga adalah larva dari lobster pasir yang memang banyak terdapat di perairan Batunampar. Larva crustacea dan Hexanauplia merupakan pemanfaat fitoplankton atau sebagai konsumen tingkat pertama (herbivore).

\section{Kualitas Air}

Saat sampling di Batunampar bertepatan dengan musim peralihan kedua. yaitu pada bulan Agustus -September. Pada musim peralihan gelombang sangat kuat dan membuat seluruh kolom air tercampur sempurna. Ini bisa dilihat dengan nilai parameter fosfat yang tinggi dan di atas baku mutu yang disyaratkan.

Bila dilihat dari parameter kualitas air fosfor, perairan pantai Batunampar sudah masuk dalam rich of nutrient waters/ perairan yang subur (P04 = 0,25 mg / l) dan kualitas airnya melebihi baku mutu Kep-MenLH No.51 tahun 2004 yang maksimum 0,015 mg / L.

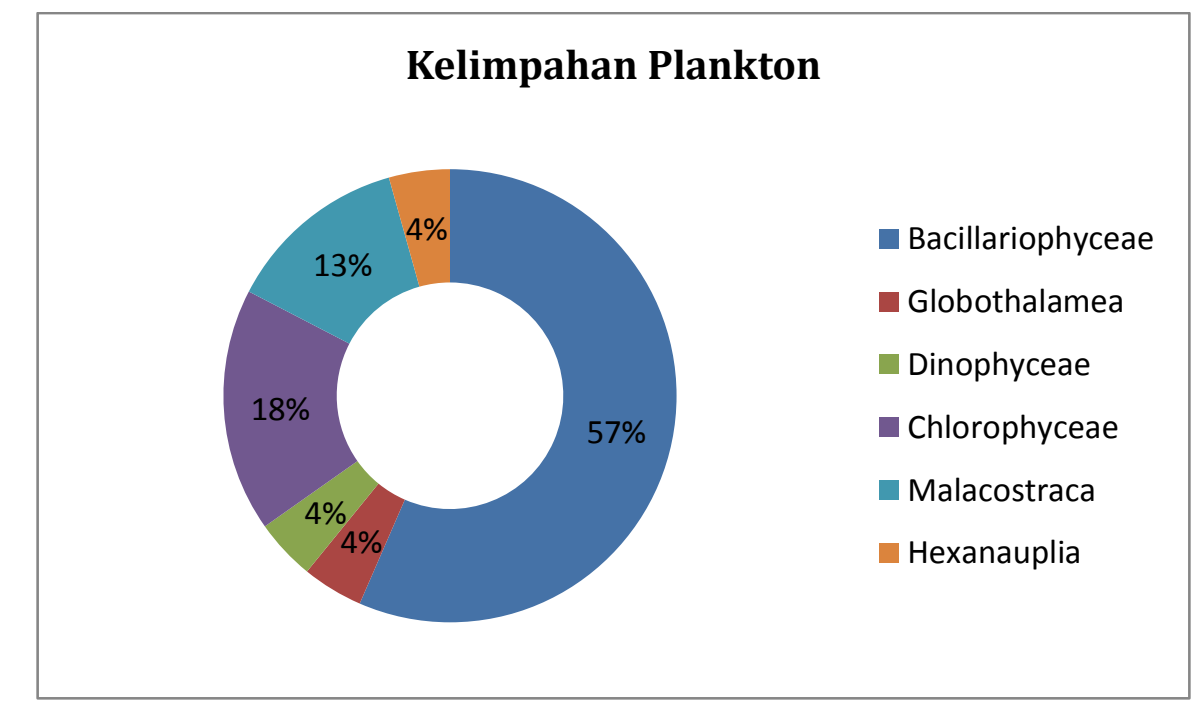

Gambar 1. Kelas dan kelimpahan plankton di kawasan KJA Batunampar

Parameter kualitas air yang lain masih berada di bawah baku mutu (Tabel 2). Berbeda dengan keadaan pada tahun 2012. Berdasarkan penelitian Junaidi et al., (2014) Teluk Ekas telah berada dalam status perairan dengan pencemaran moderat dengan 3 parameter yang di atas baku mutu yaitu parameter ammoniak, nitrat dan fosfat.

Berdasarkan hasil analisa kualitas air terlihat berbedaan yang mendasar pada beberapa parameter terutama parameter nitrogen (TAN dan nitrat). Berubahnya kualitas air yang semula pada tahun 2013 termasuk perairan subur menjadi perairan yang sedang dikarenakan pada tahun 2012- 2016 masyarakat kurang melakukan kegiatan budidaya dengan sistem KJA. Lesunya budiaya ikan system KJA karena masyarakat banyak beralih 
menangkap larva lobster yang secara ekonomis bernilai tinggi. Sedikitnya kegiatan budidaya membuat perairan bisa melakukan self purificatioi. Hasil purifikasi mandiri itu membuat parameter yang semula di atas baku mutu menjadi berkurang karena telah berubah bentuk serta digunakan oleh agen purifikasi. Keberhasilan purifikasi mandiri juga karena tidak bertambahnya masukan yang menyumbang pencemaran.

Tabel 2. Rerata Kualitas Air Kawasan KJA Batunampar

\begin{tabular}{clcc}
\hline No & \multicolumn{1}{c}{ Kualitas Air } & Batunampar & KepMenLH No.51 \\
\hline 1 & Suhu $\left({ }^{\circ} \mathrm{C}\right)$ & 25,8 & Alami \\
2 & Kecerahan (meter) & 4 & $>5$ \\
2 & pH & 8,12 & $7-8,5$ \\
3 & Dissolved Oxygen /DO (mg/L) & 5,5 & $>5$ \\
4 & Total Amonia Nitrat (mg/L) & 0,26 & 0,3 \\
5 & Fosfat (mg/L) & 0,03 & 0,015 \\
6 & Nitrat (mg/L) & 0,001 & 0,008 \\
7 & Salinitas (ppt) & 33,5 & Alami \\
\hline
\end{tabular}

\section{Indeks Lingkungan}

Indeks Keragaman $(\mathrm{H})$ plankton yang ada di Batunampar sebesar 2,64 dan indeks Dominansi $(\mathrm{D}=0,08)$. Spesies yang memiliki indeks keragaman tertinggi adalah: Synedra sp., Fragilaria sp., dan Clamydocapsa sp. (Tabel 3).

Melihat indeks keragaman yang dibawah 3 berdasarkan Abel (1979) mengindikasikan bahwa keanekaragaman plankton di perairan Batunampar khususnya kawasan KJA adalah rendah. Rendahnya keanekaragan dimungkinkan karena kondisi lingkungan yang tidak mendukung untuk hidupnya berbagai jenis plankton. Berdasarkan Radiara dan Erlania (2015) bahwa di Teluk ekas kekeruhnan bsa mencapai 25,4.NTU. Nilai kekeruhan yang tinggi merupakan salah satu faktor pembatas bagi keragaman jenis fitoplnakton yang tumbuh di sana. Kekeruahan tinggi akan menghalangi masuknya cahaya matahari ke perairan, bila cahaya terbatas maka fotosintasis akan terbatas pula.

Kondisi yang tinggi kekeruahn ini juga membuat tidak ada plankton yang dominan. Cahaya merupakan factor pembatas selain nutrient pada keragaman plankton. Karena cahaya merupakan energy yang akan disimpan melalui proses fotosintesis oleh fitoplankton yang akhirnya akan dimanfaatkan oleh zooplankton atau herbivore lainnya.

Perairan Batunampar terutama kawasan KJA termasuk daerah yang kritis berdasarkan indeks lingkungan yang dikuatkan oleh nilai kualitas ait yang diambil. Perlu penanganan khusus agar tingkat kekeruhan bisa dikurangi dengan menambahkan organisme filter feeder. 
Tabel 3. Jenis plankton dan Indeks Lingkungan di daerah KJA Batunampar

\begin{tabular}{lllrll} 
Kelas & Family & Jenis & Rerata & H & \multicolumn{1}{l}{ C } \\
Bacillariophyceae & Diatomaceae & Synedra ulna & 2 & 0.27 & 0.02 \\
Bacillariophyceae & Fragilariaceae & Fragilaria & 2 & 0.27 & 0.02 \\
Bacillariophyceae & Hemiaulaceae & Hemiaulus sinensis & 0.5 & 0.11 & 0.00 \\
& & Skeletonema & & & \\
Bacillariophyceae & Skeletonemaceae & costatum & 0.5 & 0.11 & 0.00 \\
Bacillariophyceae & Triceratiaceae & Triceratium taves & 0.5 & 0.11 & 0.00 \\
Bacillariophyceae & Coscinodiscaceae & Coscinodiscus granii & 1 & 0.18 & 0.00 \\
Bacillariophyceae & Bacillariaceae & Pseudo nitzschia & 0.5 & 0.11 & 0.00 \\
Bacillariophyceae & Lithodesmiaceae & Dytilum sol & 0.5 & 0.11 & 0.00 \\
Bacillariophyceae & Triceratiaceae & Cerataulina smithii & 0.5 & 0.11 & 0.00 \\
Chlorophyceae & Gloeocystaceae & Clamydocapsa sp & 2 & 0.27 & 0.02 \\
Bacillariophyceae & Naviculaceae & Navicula elegans & 1 & 0.18 & 0.00 \\
Bacillariophyceae & Aulacodiscaceae & Aulacodiscus gracilis & 0.5 & 0.11 & 0.00 \\
Bacillariophyceae & Stephanodiscaceae & Cydotella sp & 0.5 & 0.11 & 0.00 \\
Globothalamea & Globorotaliidae & Globorotolia pumilio & 0.5 & 0.11 & 0.00 \\
Dinophyceae & Ceratiaceae & Ceratium sp & 0.5 & 0.11 & 0.00 \\
Malacostraca & Palinuridae & larva crustacea & 1.5 & 0.23 & 0.01 \\
Hexanauplia & Pontellidae & Pontellina plumata & 0.5 & 0.11 & 0.00 \\
& & Jumlah & 15 & 2.64 & 0.08
\end{tabular}

\section{Kesesuaian Fitoplankton dengan Jenis Ikan Bandeng}

Jenis fitoplankton yang terbanyak ditemukan di Batunampar adalah Diatom. Diatom merupakan fitoplankton yang paling sering ditemukan di perairan Indonesia (Nontji, 2008).Banyaknya diatom di suatu perairan karena mempunyai kemampuan beradaptasi dengan lingkungan, bersifat kosmopolit, dan tahan terhadap kondisi ekstrim serta mempunyai daya reproduksi yang tinggi (Odum, 1971).

Berdasarkan Triyanto et al., 2014, makanan ikan bandeng beragam mulai dari fitoplankton yang didominasi oleh kelas Cyanophyceae yaitu sebesar 10,05-31,12\%, sedangkan zooplankton didominasi kelas Copepoda (3,33-27,79\%). Jenis makanan ikan bandeng bervariasi tergantung dari stadia hidup dan habitatnya. Dikemukakan bahwa makanan utama ikan bandeng dewasa terdiri dari organisme benthik dan planktonik yang terdiri dari gastropoda, lamellibranchia, foraminifera, alga filamen, diatoms, copepoda, nematoda dan detritus. Hasil penelitian Lückstädt \& Reiti (2002) terhadap kebiasaan makan juvenile bandeng di laguna air payau Kiribati pada siang dan malam hari tidak menunjukan adanya perbedaan. Hasil analisis makanan pada lambung ikan menunjukan jenis makanannya terdiri dari Chloropyhta, Cyanophyceae, Bacillariophyceae, Diatom, Crustacea, dan detritus. 
Kelimpahan Bacillariophyceae sebanyak 325 sel/L bisa dimanfaatkan oleh ikan bandeng ditambah adanya larva dari crustacean. Namun kelimpahan yang rendah yang diindikasikan oleh indeks dominansi rendah belum tentu membuat ikan bandeng mampu hidup dengan laju pertumbuhan yang baik. Maka perlu penelitian lebih lanjut akan laju pertumbuhan ikan bandeng yang budidaya di KJA untuk memanfaatkan plankton terutama fitoplankton yang ada di perairan Batunampar.

Kesimpulan dari hasil penelitian adalah :

\section{KESIMPULAN}

1. Jenis plankton yang teriventarisir pada saat penelitian adalah: Synedra ulna, Fragilaria , Hemiaulus sinensis, Skeletonema costatum, Triceratium taves, Coscinodiscus granii, Pseudo nitzschia, Dytilum sol, Cerataulina smithii, Clamydocapsa sp, Navicula elegans, Aulacodiscus gracilis, Cydotella sp., Globorotolia pumilio, Ceratium sp.,larva crustacean, Pontellina plumata

2. Plankton yang terdapat lebih banyak dari Bacillariophyceae yang merupakan jenis pakan dari ikan bandeng.

\section{DAFTAR PUSTAKA}

Abel, P.D. (1989). Water Pollution Biology. London. John Wiley and Sons Ltd.

Cokrowati, N., Junaidi, M., \& Diniarti, N. (2015). Potensi Habs (Harmful Algal Bloom) Pada Perairan Batu Nampar Lombok Timur. Laporan Penelitian. Universitas Mataram. Mataram

Junaidi, M., Andayani. S., Mahmudi, M., Sartimbul, A. (2014). Organic Matter Degradation in Lobster Culture System and Their Effect on Water Quality in Ekas Bay, Indonesia. Journal of Applied Biotechnology, 2, No.1.

Nontji, A. 2008. Plankton laut. Pusat Penelitian Oseanografi. Lembaga Ilmu Pengetahuan Indonesia (LIPI).LIPI Press. 331 hal.

Odum, E.P. 1971. Fundamentals of Ecology. Third edition. W.B. Saunders Company, Philadelphia, London,Toronto, $574 \mathrm{pp}$.

Odum EP. 1993. Dasar-Dasar Ekologi. Ed Ke-3. Yogyakarta: Gajahmada University Press.

Omura, T. Mitsunori Iwataki, Valeriano M. Borja, Haruyoshi Takayama, Yasuwo Fukuyo. 2013. Marine phytoplankton of the western pasific. Kouseisha Kousekaku. Japan.

Setyowati, D.N., N. Diniarti, S.Waspodo. 2013. Pengembangan Budidaya Laut Secara Berkelanjutan Dengan Sistem., Integrasi Di Perairan Teluk Ekas : Studi Budidaya Lobster (Panulirus Homarus) Dan Abalon (Haliotis Assinina). Laporan Penelitian. Universitas Mataram.

Triyanto, M. Mukhlis Kamal, dan Niken TM. Pratiwi. 2014. Pemanfaatan Makanan Dan Pertumbuhan Ikan Bandeng (Chanos Chanos) Yang Diintroduksi Di Waduk Ir.H. Djuanda, Jawa Barat. Limnotek; 21 (1). 